\title{
A new pricing model of China's parallel rail lines under the diversified property rights
}

\author{
Shaoni Zhou, Qiusheng Zhang, Xiaowei Wu \\ Beijing Jiaotong University (China) \\ snzhou@,bjtu.edu.cn, qsz̧hang@,bjtu.edu.cn;09120875@,bjtu.edu.cn
}

Received November 2012

Accepted February 2013

\section{Abstract:}

Purpose: The purpose of this paper is to study on the pricing of China railway company under the background of diversified property rights, especially the pricing of the parallel line system that belong to different owners.

Design/methodology/approach: Through theoretical analysis of the main influential factors of railway pricing, this paper designs a basic quotation system for the parallel railway lines.

Findings: The transaction price of parallel line consists of two parts, which are fixed railway network price and variable network using price.

Practical implications: Through the reasonable designing of fixed network price and variable network using price, it can not only lead to high profitability and low government subsidy, but also can ensure remaining more railway network resources and fulfill the social responsibilities.

Originality/value: The conclusions of this study will lay the foundation for the harmonious development of Chinese railway network under the diversified property rights.

Keywords: Diversified Property Rights, Parallel Rail Lines, Pricing Model 


\section{Introduction}

According to the medium-term and long-term railway adjusting project, a rapid growth will last in the nationwide railway network in the next decade. The transport capacity will meet the needs of economic and social development, and the key technology and equipment will reach or close to the international advanced level. Such a large scale of investment will inevitably need to further expand the scale of the joint venture in rail construction, and the diversified property rights has become an inevitable trend. In the period of which the railways were entirely belonged to the state, the cost of the rail network is seen as internal costs and without independent accounting. While under the background of diversified rail network ownership, the pricing of the rail network affects not only the income and cost of the rail infrastructure enterprises and transportation enterprises, but also the competition and cooperation of the different rail infrastructure companies. Most of all, because the parallel lines which belong to different owners provide similar service which can be easily substituted, competitions will arise between different producers. It is urgent to solve the problem of how to realize fair competition for the national railway and joint venture railway. Based on these preconditions, this paper will study on the pricing model of using fees under the situation of diversified property rights.

\section{Practices of the rail network pricing and relevant literatures review}

\subsection{Rail network pricing practice around the world}

In America, the railroad system is mainly used to undertake the freight, thus most of the railway companies are freight companies, which railway lines have taken up a high proportion of the current U.S. business lines. As a result, the problem is that the passenger transport companies should pay for the using of the railway which owned by the freight transport company. In determining the cost compensation for rail network, it mainly reflects the idea of subsidy-free pricing. That is, the transport facility users should compensate for the full cost. There is no obligation for the government to offer subsidy to infrastructure construction and its operation. In the actual market, the charge on the cross-road transportation is determined by daily negotiations.

In European rail network pricing practice, different methods are adopted in various countries: in the Nordic countries (Sweden, Finland, Denmark, etc.), the rail network charge is based on marginal cost; in Germany and France, it is based on the average cost. Since the marginal cost-based charge is usually lower than that of average cost-based, the Nordic country governments need to provide a lot of subsidy for the rail network companies. 
Chinese railways have been fully owned by the state for a long time. The Ministry of Railways acts as both a government department to implement the national rail management function and a market player to provide complete rail transportation products. In financial practice, the Ministry of Railways also works as an accounting body as a whole, therefore the rail network fees become an internal transaction costs and cannot be defined clearly. Based on this, the rail network fees, having been "digested" within the railway system for a long-term, had been ignored for a long time. In 2001, railways began to implement the policy of "separation of rail network and transportation" internally and split accounting system between passenger and freight companies, which led to the passenger transportation entering the rail charging system. In this system, the standards of the rail line using fees is formulated by the Ministry of Railways according to the train kilometers, taking into consideration of the line class, the train grade and grouping size.

\subsection{Relevant literatures review}

There have been many literatures on properties, property of railway enterprises and property theory in railway pricing practice.

Coase studies property and points out that private enterprises are more efficient than state enterprises in resources allocation (Coase, 1960). Wang Engui and Wang Jiaqiong address an idea in their paper that Chinese government should speed up the structural reform of railway investment, amend the railway law, guarantee law, corporation law, taxation law and other related laws, and make particular privilege policies and clean off the legal impediments in railway construction for non-governmental capital in China, to solve the problem of capital scarcity and offer another investment opportunity for non-governmental capital in China (Engui \& Jiaqiong, 2003).

Although the Ministry of Railways has begun to encourage the non-governmental capital to invest in railway construction, the effect is not obvious in practice. In order to find out the reason for this phenomenon, Rong Chaohe has given his opinion that railway investment and financing system should not only focus on the financing level, but also should challenge the old system formation of government-control (Chaohe, 2006). Liu Xia attributes this to the current system arrangement in railway. She thinks that the Railway Bureau can easily invade the benefits of the joint-venture enterprise (Xia, 2007). Li Wenxin, Liang Fang \& Shi Benshan give their points of that the Railway Bureau would select "locked-in" as the most excellent strategy after the social capital invested in the railway construction, so what the external capital can do is only to reject investing in the railway construction (Wenxin, Fang \& Benshan, 2010). 
Zhao Jian believes that traffic flow regulation right is the most important element of railway property (Jian, 2007). Li Minghui and Zhao Jian also point out that the real reason for the external capital investors to leave the railway market is that they cannot share the synergy value (Minghui \& Jian, 2008).

On railway pricing method, Li Daian thinks that the railway network facilities are public goods, so the government should pay for the cost of the goods (Daian, 2006). Francisco C. \& Juan D. O., Henrik A. \& Mikael O. also suggest that the railway pricing should connect with the cost, while presently, only a small portion of costs are recovered via charges (Francisco \& Juan, 2011), (Henrik \& Mikael, 2007). Christina N., Zhang Hanbin \& Tan Yan, Qian Chunyan etc. study the railway charging method in different countries and areas (Christina, 2008), (Hanbin \& Yan, 2011), (Chunyan, 2010). Besides these, there are still some literatures on models of travel route selection. For example, Li Mi etc. and ZHU Xiaodong etc., suggest such models, but they are mainly on urban traffic (Mi, 2011), (Xiaodong, 2012).

Based on these literatures, this paper will try to give some suggestions on fair competition of the parallel railway by different capital sources from different pricing model.

\section{Basic relationship of the rail network pricing under the background of the diversified property rights}

Both the European rails complete separation of network and transportation and the American Rails incomplete separation, their rail management systems are both in a mature market economy.

The railway development has led to strong financing needs, and the scale of the joint ventures will be further expanded. Correspondingly, Chinese rail network pricing also needs to establish a market pricing mechanism which can adapt to the overall requirements of railway diversified ownership and can properly handle the relationship among different stakeholders.

Under the diversified property rights of Chinese rail network, rail networking quoting stakeholders can be divided into three hierarchies. Their relationships are shown in Figure 1. The first level is the Ministry of Railways, whose goal is focused on the national railway development, and at the same time, reducing the level of financial subsidies as much as possible; the second level is the railroad bureau and outside investors. The goal of the Railway Bureau is the completion of the performance evaluation of the Ministry of Railways and the transport task, while external investors pursue gain a higher rate of return on the investment; the third level includes the state-owned rail companies, the joint venture rail companies and transportation companies. The rail companies' goal is to improve the supply efficiency level of the rail network resources, while the transportation companies' goal is to obtain the largest 
benefits from the rail network resource through negotiations with the rail network service provider.

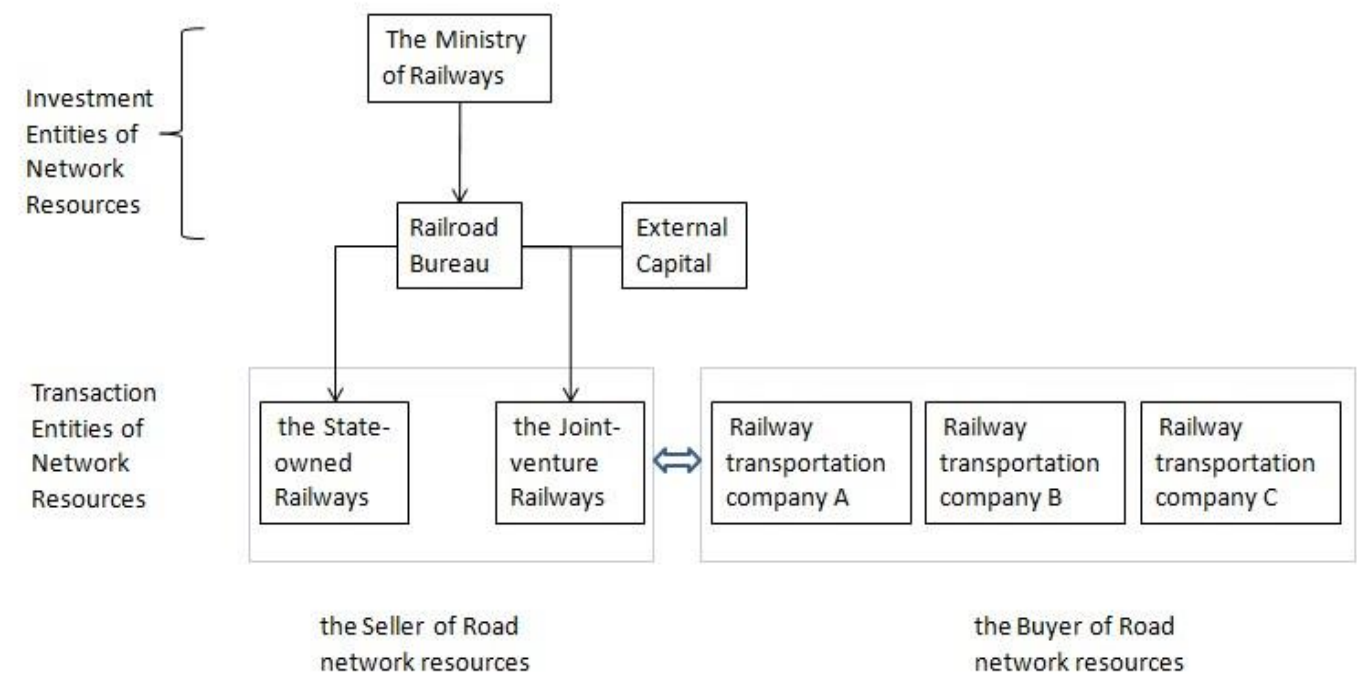

Figure 1. Stakeholders in Rail Network Pricing

Therefore, the pricing mechanism of the rail network under the diversified ownership really impacts these stakeholders and must emphasize their interests. The reasons are as follows:

Firstly, as the sellers of network resources who provide similar displacements services, the state-owned railways and joint-venture railways should make decision independently and develop a competitive quoting system which will help to improve the service level and control costs of railway companies.

Secondly, transportation companies act as the buyer of rail network resources, should have an independent bargaining rights and the ability to seek the lowest bid seller of rail network resources.

Thirdly, the Ministry of Railways will strive to reduce the level of subsidy which may be only given to the railway network company, for which there is more cost sank relative to other transportation companies.

Fourthly, being a rational investment entity, the external capital will investigate the income of the rail network and the government subsidies when making the decision of investing to the railway line. If the realized return overweighs the cost of the investment, the investors would choose to invest. Otherwise, they will give up. 


\section{Analysis of the influential factor of the rail network pricing}

\subsection{Cost factor}

The price of any goods or services can be regarded as compensation of its cost in transaction. The more we consume social resources, the higher price of goods and services it should have. Otherwise there will be no manufacturers or service providers.

Taking into account the actual situation of Chinese railway development, the cost of the rail network can be defined into the following five levels. First: the variable operating cost of the rail network; Second: the variable and fixed operating cost of the rail network (excluding the interest expense); Third: the full operation cost of the rail network; Fourth: the full operation and construction costs of the rail network; Fifth: the full operation and construction costs of the rail network and the equity cost of it.

\begin{tabular}{|c|c|c|c|c|c|}
\hline & $\begin{array}{l}\text { the variable } \\
\text { cost of the } \\
\text { operating } \\
\text { costs }\end{array}$ & $\begin{array}{l}\text { The fixed part of } \\
\text { the operating } \\
\text { costs(excluding the } \\
\text { interest expense) }\end{array}$ & $\begin{array}{l}\text { the } \\
\text { interest } \\
\text { expense }\end{array}$ & $\begin{array}{c}\text { the fixed } \\
\text { investme } \\
\text { nt }\end{array}$ & $\begin{array}{l}\text { the average } \\
\text { profit margins } \\
\text { of society }\end{array}$ \\
\hline the first level & $\checkmark$ & & & & \\
\hline the second level & $\checkmark$ & $V$ & & & \\
\hline the third level & $\sqrt{ }$ & 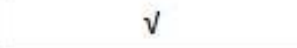 & $v$ & & \\
\hline the fourth level & $\sqrt{ }$ & $\checkmark$ & $v$ & $v$ & \\
\hline the fifth level & $v$ & v & v & $v$ & $v$ \\
\hline
\end{tabular}

Figure 2. Level Graph of Rail Network Cost

The fourth level is the traditional accounting cost and the fifth level is the economic cost.

\subsection{Supply and demand factors}

The supply-demand relationship is referred to the relationship between production and consumption in the market. In private market economy, the deviation of price from value spontaneously adjusts supply and demand. If supply exceeds demand, prices will decrease; if demand exceeds supply, prices will increase.

The rail network resource is a special service whose supplier is the railway infrastructure company and the consumer is the railway passenger and freight transport company. Its 
supply-demand relationship is influenced not only by very two sides, but also by external factors, such as the redundancy degree of social capital, the average profit margins of society, limits on the prices and subsidies from government.

\subsection{Government factor}

In actual economic environment, expect for the invisible hand of the market, there is also the visible hand of the government. Especially when the natural monopoly characteristics of public goods are involved, the government's actions will largely affect the price of services and investor returns. Government's influences on rail services are reflected in the following two aspects.

First, the government can set the price of transport services. The government always controls the price by providing the highest price or lowest price regulation, thereby affecting the market demand and the relationship between demand and supply.

Second, the government can implement the price subsidies. For public goods, the government always consider the maximize efficiency of the entire socio-economic by providing subsidies. The extent of subsidies is usually determined by the degree of cost compensation.

\section{The pricing model of the parallel rail lines}

The pricing model should be in line with market mechanism and suitable for the parallel rail lines.

\subsection{Specific conditions of the pricing model}

The model should possess the following basic conditions when applied to the parallel rail line.

Firstly, the rail network service providers are state-owned railways and joint-venture railways, and there are a large number of rail network service buyers.

Secondly, there are two forms to purchase the rail network resources. The first is the negotiation at a fixed time that the buyers buy the rail network services based on forecast of future transport demand for a fixed period; the second is temporary negotiations that the buyers buy the rail network services according to the provisional transport plan which will be more expensive because it requires the rail network providers to provide temporary marshalling and deployment of network resources and will not be investigated further in this article. 
Thirdly, the fixed period purchase price includes two parts: one is in the form of rail network card, which is a fixed cost and provides the buyer the right of using the network in the range of a certain passage; another part is in the form of user fees, which is a variable costs by paying the network usage fees according to the actual mileage, speed, load and the rail grade.

\subsection{Construction of the pricing model}

\section{The pricing mechanism}

The state-owned railway and the joint venture railway both proposed their rail network card price, which are $w_{1}$ and $w_{2}$, and rates of fee for per unit are $\omega_{1}$ and $\omega_{2}$. The card price of the state-owned rail network is lower than that of the joint venture rail network, that is $w_{1}<w_{2}$, but the rates of fee for per unit of the state-owned rail is higher than that of the joint venture rail, that is $\omega_{1}>\omega_{2}$. These will produce the equilibrium point of the train traffic volume in the transaction of the railway resources. That is, when the train traffic volume is on this point, the transaction price of the rail resources is the same no matter one chooses the state-owned rail or the joint venture rail, when it comes to the actual train traffic volume, it is cheaper to choose the joint venture rail, on the contrary, it is cheaper to choose the state-owned railway. Those are shown in figure 3 below. The equilibrium point is $\alpha^{*}=\frac{\mathrm{w}_{1}-\mathrm{w}_{2}}{\omega_{1}-\omega_{2}}$.

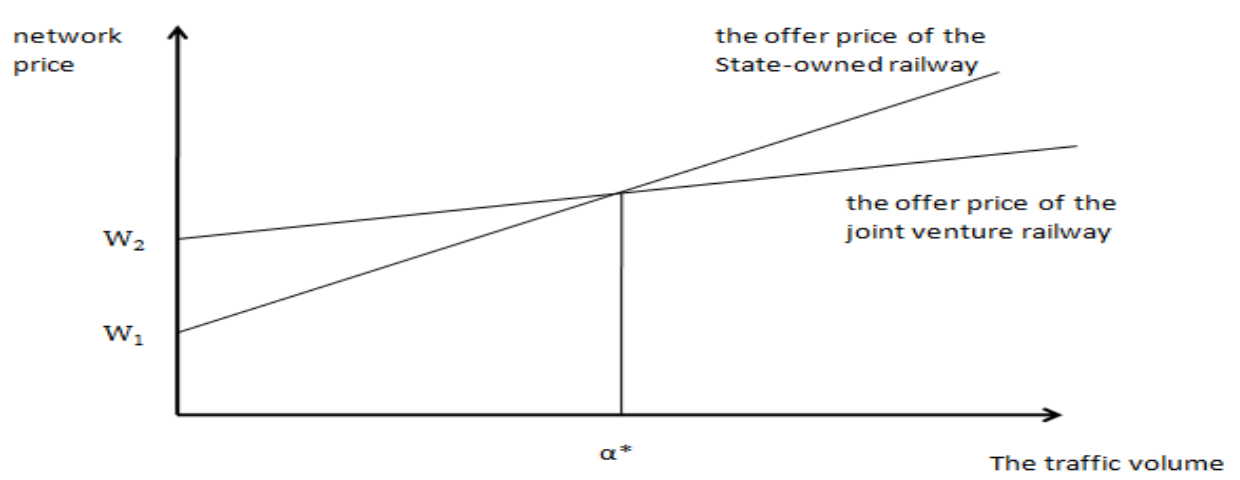

Figure 3. Offering Mechanisms of Network Resources

This quotation mechanism has three notable characteristics which will be shown in the following part.

Firstly, the quotation mechanism of the rail network trading price can be divided into two parts, which are the fixed card price and the variable fee of using rail network, which can be understood as that the fixed card price is the compensation for the rail infrastructure costs of and the fixed operating costs, and the variable use fee part is the compensation for the 
variable operating costs. These reflects the fact that different income corresponds to different costs, and this division can give a more clear definition of the degree of compensation for different nature of costs, thus provide a reasonable reference when formulating the subsidies mechanism for the government.

Secondly, this quotation system encourages the company with more train traffic to choose the joint-venture railways. Because the joint venture rail network resources can be utilized more efficiently and the actual profitability can be improved then, which will attract more external capital investment on the railways as well.

Thirdly, this quotation system makes the state-owned railway have more remaining rail network resources and can satisfy the temporary transport demand. In this way, when there is a temporary emergency situation, such as earthquake relief, which needs rail transport, it can be realized by using the state-owned railway resources. The social responsibility of the stateowned railway can be completed without sacrificing the interests of the joint venture railways.

\section{Subsidy mechanism}

As the quotation system described above, the rail transport companies can be divided into two categories, one is those choosing the state-owned rail network resources, with a total number of $m$, each traffic amount isa $a_{1, i}(i=1 \ldots m)$, the other is those choosing the joint-venture rail network resources, with a total number of $n$, each traffic amount is $a_{2, j}(j=1 \ldots n)$.

The annual income of the state-owned railway is:

$$
\mathrm{R}_{1}=\mathrm{m} \times \mathrm{w}_{1}+\sum_{i=1}^{m} \alpha_{1, i} \omega_{1}
$$

The annual income of the joint-venture railway is:

$$
\mathrm{R}_{2}=\mathrm{n} \times \mathrm{w}_{2}+\sum_{j=1}^{n} \alpha_{2, i} \omega_{2}
$$

Supposing the service life of the state-owned railway and the joint-venture railway is $\mathrm{M}$ and $\mathrm{N}$, the total income of the state-owned railway is:

$$
T R_{1}^{M}=\sum_{I=1}^{M} R_{1}^{I} \quad(\mathrm{I}=1 \ldots \mathrm{M})
$$

The total income of the joint-venture railway is:

$$
T R_{2}^{\mathrm{N}}=\sum_{J=1}^{N} R_{2}^{J} \quad(\mathrm{~J}=1 \ldots \mathrm{M})
$$

The variable operating cost of the state-owned railway is:

$$
V C_{1}=\sum_{i=1}^{m} \alpha_{1, i} c_{1}
$$


$\mathrm{c}_{1}$ represents the cost per transportation volume;

The variable operating cost of the joint-venture railway is:

$$
V C_{2}=\sum_{j=1}^{\mathrm{n}} \alpha_{2, j} c_{2}
$$

$\mathrm{C}_{2}$ represents the cost per transportation volume;

For the state-owned railway, the fixed operating cost (excluding the interest cost) is $\mathrm{OC}_{1}$, the annual interest cost is $\mathrm{FI}_{1}$, and the fixed investment on the rail network construction is $\mathrm{FC}_{1}$; for the joint-venture railway, the fixed operating cost (excluding the interest cost) is $\mathrm{OC}_{2}$, the annual interest cost is $\mathrm{FI}_{2}$, and the fixed investment on the rail network construction is $\mathrm{FC}_{2}$.

The total cost of the state-owned railway is:

$$
\mathrm{TC}_{1}=\sum_{I=0}^{\mathrm{M}}\left(V C_{1}^{I}+O C_{1}^{I}+F I_{1}^{I}\right)+F C_{1}
$$

The total cost of the joint-venture railways is:

$$
\mathrm{TC}_{2}=\sum_{J=0}^{\mathrm{N}}\left(V C_{2}^{J}+O C_{2}^{J}+F I_{2}^{J}\right)+F C_{2}
$$

Under the circumstance of no expansion of production, the government subsidy to the stateowned railway and the joint-venture railway are $s_{1}$ and $s_{2}$ respectively, the average social profit margins is $r$, the external equity investment of the joint-venture railway is $\gamma$, so the goal of the governmental subsidy is:

$$
\begin{aligned}
& S_{1}+R_{1} \geq V C_{1}+O C_{1}+F I_{1} \\
& S_{2}+R_{2} \geq V C_{2}+O C_{2}+F I_{2}+F C_{2} \times \gamma \times r
\end{aligned}
$$

So, it can be concluded that:

$$
\begin{aligned}
& S_{1} \geq \sum_{\mathrm{i}=1}^{\mathrm{m}} \alpha_{1, \mathrm{i}}\left(\mathrm{c}_{1}-\omega_{1}\right)+O C_{1}+F I_{1}-m w_{1} \\
& \mathrm{~S}_{2} \geq \sum_{\mathrm{j}=1}^{\mathrm{n}} \alpha_{2, \mathrm{j}}\left(\mathrm{c}_{2}-\omega_{2}\right)+O C_{2}+F I_{2}+F C_{2} \times \gamma \times \mathrm{r}-n w_{2}
\end{aligned}
$$

Under the circumstance of minimum government subsidy, the equilibrium will be reached, function (11) will be like follows:

$$
\mathrm{S}_{1}=\mathrm{VS}_{1}+\mathrm{FS}_{1}=\sum_{\mathrm{i}=1}^{\mathrm{m}} \alpha_{1, \mathrm{i}} \mathrm{c}_{1}\left(1-\frac{\omega_{1}}{\mathrm{c}_{1}}\right)+\left(\mathrm{OC}_{1}+\mathrm{FI}_{1}\right)\left(1-\frac{\mathrm{mw}_{1}}{\mathrm{OC}_{1}+\mathrm{FI}_{1}}\right)
$$

In this equation, $\mathrm{VS}_{1}$ and $\mathrm{FS}_{1}$ are referred to the variable cost subsidy and the fixed cost subsidy respectively. It can be calculated that the variable cost subsidy rate is $\frac{\omega_{1}}{c_{1}}$ for stateowned railway companies, the government subsidy rate is $\left(1-\frac{\omega_{1}}{c_{1}}\right)$; the fixed cost subsidy is $\frac{\mathrm{mw}_{1}}{\mathrm{OC}_{1}+\mathrm{FI}_{1}}$, the government subsidy rate is $\left(1-\frac{m w_{1}}{O C_{1}+F I_{1}}\right)$. 


$$
S_{2}=V S_{2}+F S_{2}=\sum_{j=1}^{n} \alpha_{2, j} c_{2}\left(1-\frac{\omega_{2}}{c_{2}}\right)+\left(O C_{2}+F I_{2}+F C_{2} \times \gamma \times r\right)\left(1-\frac{n w_{2}}{O C_{2}+F I_{2}+F C_{2} \times \gamma \times r}\right)
$$

In the above equation, $\mathrm{VS}_{2}$ and $\mathrm{FS}_{2}$ are represented variable cost subsidy and the fixed cost subsidy respectively. It can be calculated that the variable cost subsidy rate is $\frac{\omega_{2}}{c_{2}}$ for the railway joint venture companies, the government subsidy rate is $\left(1-\frac{\omega_{2}}{c_{2}}\right)$; the compensation rate for the fixed cost and economic profit is $\frac{n w_{2}}{O C_{2}+F I_{2}+F C_{2} \times \gamma \times r}$, the government compensation rate is $\left(1-\frac{n w_{2}}{O C_{2}+F I_{2}+F C_{2} \times \gamma \times r}\right)$.

\subsection{Evaluation on this pricing model}

\section{Function of government}

In the basic model, the government needs to find the equilibrium point in a certain way, in order to determine the transport volume in the quotation system, which is an important factor to the operating income for both the state-owned railways and joint-venture railways, thereby affecting the government actual subsidy level. It would be a better operation mode for the joint-venture railway that the rail network card price $w_{2}$ and the unit charge $\omega_{2}$ can be decided though improving modern corporate governance structure. While, the state-owned railway can determines the unit charges $\omega_{1}$ according to its variable costs. The government sets the price of state-owned rail network card $\mathrm{w}_{1}$ according to the forecasted total social demand between the two service nodes.

In addition, government can attract more external capital investment by choosing the investment event with high level of incomes, which will not only reduces the level of government subsidies $S_{2}$, but also increases the market competitiveness of joint-venture railways.

\section{Time factor}

In the basic model, the quotation mechanism is once a year and the rail transport company will select the rail network company based on the needs of the next year's transportation. But this does not take this case into account, that is, the annual demand for transport is not distributed equally to each month, but with a certain periodicity. From this perspective, if the frequency of quotation mechanisms is higher, such as once a month, it would be more 
reasonable. However, it will also increase the total negotiation cost if the offer mechanism is too often.

\section{Confirming of the average social profit margin}

In the basic model, an important exogenous variable is the average social profit margin. On the one hand, it is an opportunity cost for external capital. If the profit margin of investment in the railway is lower than the average social profit margin, the railway is not worth investing. On the other hand, it is the key factor to decide whether the government should give subsidy to the joint venture railway and how much to give.

\section{Problems of forecast accuracy}

The most important decision that the Ministry of Railways has to make is to give the stateowned rail network card price and the equilibrium point of transport volume based on the future transport demand forecast, the rail network card price $w_{2}$ and the unit charges $\omega_{2}$ of the joint-venture, the state-owned railway unit charge $\omega_{1}$. By the transport company's choice, the total social transport demand between the two service nodes can be distributed spontaneously. Ideally, the passenger or freight transport company which has a large requirement should choose the joint-venture railway, and the company of passenger or freight transport which has a small requirement should choose the state-owned railway. Therefore, in order to let the market's selection to be well-ordered, there is a higher requirement on the forecast accuracy of future transport demand. Methods to improve the prediction accuracy include the following two, but not limited to them: the first is the trial offering system, that is before the formal rail network bidding, there is a process to ask price, and then work as the reaction of the market to the process of formal network quotations; the second method is to raise the frequency of offering mechanism, such as once a month, which can improve the accuracy of the forecast in a certain extent.

\section{Rail network card pricing method}

The price of the rail network card can be further considered from two perspectives. On the one hand, we can learn from the practice of the European rail network reform and development. Different levels of price should be established according to the rail line grade, and the train level. This is also in line with the basic value law that the more network resources on one consuming, the more one should pay and the higher the rail network card price is); on the other hand, we can set the rail network card price according to the different transport volume of the rail transportation company. This is more in line with the economics of differential pricing, that is, the full access to consumer surplus, consumers here is the rail transportation company. For producers, such as the state-owned rail network company and the joint-venture 
rail network company, the meaning is to obtain the consumer surplus as much as possible and reduce government subsidies and the government participation in market activities.

\section{Conclusions}

It is a corollary that the financing bottleneck of the railway development decides the diversification of China's railway investment entities. In order to attract the external capital investors to invest in the railway construction, the mode of operation led by the existing Ministry of Railways must be changed, and it is necessary to establish the market-oriented pricing mechanism of the rail network.

Firstly, this paper has analyzed the stakeholders and their relationships under the rail network pricing of the diversified property, and designs a clear mechanism of competitive quotation among the sellers, and the buyers should have an independent bargaining rights and negotiation capacity. Based on the above conditions, the Ministry of Railways can reduce subsidies to the rail network companies.

Secondly, this paper has analyzed the main influencing factors of the rail network pricing, which include cost factors, demand and supply factors and government factors.

Finally, this paper has constructed the basic pricing model for parallel rail lines, defined the specific conditions of the model from the aspects of the characteristics of the transaction parties, the transaction formation and the composition of the price, and also made explanations of the basic model from the perspective of pricing mechanisms and subsidy mechanisms.

\section{References}

Chaohe R. (2006). Boosting railway investment institutional reform in China from property relations. Comprehensive Transportation, 1, 32-36.

Christina N. (2008). User charges for the railway infrastructure in Bulgaria, Transportation Research Part A. Policy and Practice, 42(3), 487-502. http://dx.doi.org/10.1016/j.tra.2008.01.015

Chunyan Q., Fang W., \& Zhicheng L. (2010). Price discrimination method and its use in railway transport of passenger. Railway Operation Technology, 1, 16-20.

Coase R. H. (1960). The problem of social cost. Journal of Law and Economics, 3(10), 1-44. http://dx.doi.org/10.1086/466560 
Daian L. (2006). Research on the pricing problems of the railway infrastructure. Comprehensive Transportation, 7, 36-39.

Engui W., \& Jiaqiong W. (2003). Legal impediments of non-governmental capital participating in rail way construction in China. Journal of Northern Jiaotong University (Social Sciences Edition), 2(3), 15-19.

Francisco C., \& Juan D. (2012). Are rail charges connected to costs. Journal of Transport Geography, 22(5), 28-33.

Hanbin Z., \& Yan T. (2011). Railway rate regulation in America and its enlightenment on our country. Rail Way Transport and Economy, 11, 49-52.

Henrik A., \& Mikael O. (2007). Noise charges in railway infrastructure: A pricing schedule based on the marginal cost principle. Transport Policy, 14(3), 204-213. http://dx.doi.org/10.1016/j.tranpol.2007.01.002

Jing H. (2008). Railway infrastructure pricing in Europe. Chinese Railways, 12, 55-59.

Jian Z. (2007). Relationship among the united schedule, the railway property and the transportation efficiency. Comprehensive Transportation, 11, 13-17.

Mi L., Xia W., \& Xianjun G. (2011). Travel route model under traffic congestion environment based on reliability, AISS, 3(8), 179-185. http://dx.doi.org/10.4156/aiss.vol3.issue8.22

Minghui L., \& Jian Z. (2008). Synergy value: Crucial reason for difficulty of railway investing and financing in China. Comprehensive Transportation, 5, 9-14.

Wenxin L., Liang F., \& Benshan S. (2010). Analysis based on the financing difficulties of lockedin joint-venture railway. Journal of Southwest Jiaotong University (Social Sciences), 2, 53-55.

Xiaodong Z., Hongcheng G., Chen L., \& Chongjun F. (2012). Modeling traffic model driven route choice simulator in UML, JDCTA, 6(5), 141-149. http://dx.doi.org/10.4156/jdcta.vol6.issue5.17

Journal of Industrial Engineering and Management, 2013 (www.jiem.org)

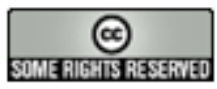

El artículo está con Reconocimiento-NoComercial 3.0 de Creative Commons. Puede copiarlo, distribuirlo y comunicarlo públicamente siempre que cite a su autor y a Intangible Capital. No lo utilice para fines comerciales. La licencia completa se puede consultar en http://creativecommons.org/licenses/by-nc/3.0/es/ 